\section{Raízes}

$\overline{\text { Vol. 25, } \mathrm{N}^{\mathrm{o}} \text { s } 1 \text { e 2, jan.-dez./2006 }}$

Trabalho recebido em:

25/03/2007

Aprovado para publicação em: 22/06/2007
Maurílio de Abreu Monteiro

Doutor em Desenvolvimento Sócio-Ambiental. Professor do Núcleo de Altos Estudos Amazônicos (NAEA/UFPA).E-mail: maurilio_naea@ufpa.br

Sheila do Socorro Lima Teixeira

Mestre em Planejamento do Desenvolvimento. Núcleo de Altos Estudos Amazônicos,

NAEA/UFPA.E-mail: geosslt@yahoo.fr

\title{
MINERAÇÃO INDUSTRIAL E A ESTABILIDADE DE ASSENTAMENTOS RURAIS NO SUDESTE DO ESTADO DO PARÁ, BRASIL
}

\begin{abstract}
RESUMO
No sudeste paraense houve o encontro de duas frentes de produção, a camponesa e a mineral, especialmente a partir da década de 1970, quando passaram a sofrer pressões e influências recíprocas. Neste contexto, o artigo analisa o papel das atividades mineradoras exercidas sobre a estabilidade da produção camponesa em quatro assentamentos localizados no município paraense de Parauapebas, Brasil. O artigo aponta que as dinâmicas decorrentes da instalação de grandes empreendimentos mineiros contribuíram para atrair populações de origem camponesa, reforçando a busca pela terra na região, retirar filhos dos assentados dos seus lotes, reduzindo a força de trabalho disponível para sustentar a produção familiar. Por outro lado, surgiram facilidades de comercialização de produtos da agricultura familiar, devido à demanda crescente. $\mathrm{O}$ artigo conclui indicando que, da interação com a mineração, surgem dinâmicas contraditórias no que concerne à estabilidade da produção camponesa nos assentamentos rurais estudados.
\end{abstract}

Palavras chave: mineração, agricultura familiar, Amazônia

\section{INDUSTRIAL MINING AND THE STABILITY OF RURAL SETTLEMENTS IN THE SOUTHEAST OF THE STATE OF PARÁ, BRAZIL}

\begin{abstract}
There were two production frontiers in the southeast of the State of Pará, Brazil: farming and mining. Particularly as of the 1970's, both began to influence one another. Within this context, this paper analyzes the role of mining activities in the farming production stability through the study of four settlements, located in the municipality of Parauapebas, State of Pará, Brazil. The article identifies the dynamics which resulted from the building of large mining operation plants, which on their turn attracted peasant populations looking for land, and then allured farmers' children out of their settlements, thus reducing the labor force needed to sustain family agricultural units. On the other hand, the trade of agricultural goods produced by the families began to increase due to a growing demand. The conclusion indicates that opposing dynamics emerge from the interaction between mining and farming activities, affecting farming production stability in the studied rural settlements.
\end{abstract}

Key words: mining, peasant, Amazon

\footnotetext{
* A elaboração deste artigo contou com a colaboração do MCT/CNPq, a quem os autores são gratos.
} 


\section{INTRODUÇÃO}

No sudeste do Estado do Pará a produção camponesa e a produção mineral têm sofrido pressões e influências recíprocas, pois, a partir da década de 1970, ocorreu uma intersecção temporal e geográfica destas estruturas produtivas. A região abrigou frentes de expansão camponesa (Velho, 1979) que foram reforçadas pela abertura de rodovias, a exemplo da Transamazônica e da PA-150. Houve um grande fluxo migratório, notadamente o de populações camponesas na região, bem como se instalaram empreendimentos de mineração industrial vinculados à Companhia Vale do Rio Doce (CVRD) e que se destinavam à extração e beneficiamento primário de minerais. Estes empreendimentos têm influência nas trajetórias do espaço agrário da região.

A região, em função da instalação de atividades de mineração industrial e da concentração de grande fluxo migratório, passou a assumir, simultaneamente, uma conotação de área de crescente exploração de minerais e de surgimento de projetos de assentamentos (Figura 1).

Se as repercussões da mineração industrial e da agricultura familiar per si sobre a socioeconomia regional encontram diversidade de interpretações, as análises das interações entre elas são ainda muito incipientes.

Neste trabalho, designa-se agricultura familiar aquela na qual a posse da terra é de até 200 ha e que recorre à força de trabalho familiar sempre superior a $80 \%$ das atividades (Costa, 1994). Na região em estudo, a estruturação da agricultura familiar ganha mais relevância por meio de estruturação de Projetos de Assentamentos PA - surgidos como decorrência da pressão dos movimentos sociais e da atuação do Instituto Nacional de Reforma Agrária (INCRA). No âmbito das ações do INCRA foram criados, às proximidades da Serra dos Carajás, sudeste paraense, diversos assentamentos. A dinâmica de interação de assentamentos com a mineração in- dustrial é analisada em quatro deles, a saber: Palmares I, Palmares II, Carlos Fonseca e Onalício Barros.

\section{VisÕEs SOBRE A ESTABILIDADE DA AGRICULTURA FAMILIAR NA REGIÃO}

No que concerne à contribuição da agricultura familiar para processos de desenvolvimento regional, há interpretações contraditórias. Serrão (1995), Homma (1998), Walker (1996), por exemplo, argumentam que a produção camponesa, nos padrões praticados na região de $\mathrm{Ca}$ rajás, atua como "mineradores de nutrientes" sendo, portanto, instável e comportando, neste momento, os moldes de uma fronteira agrícola em movimento. Não contribui como atividade que fortaleça processos de desenvolvimen-

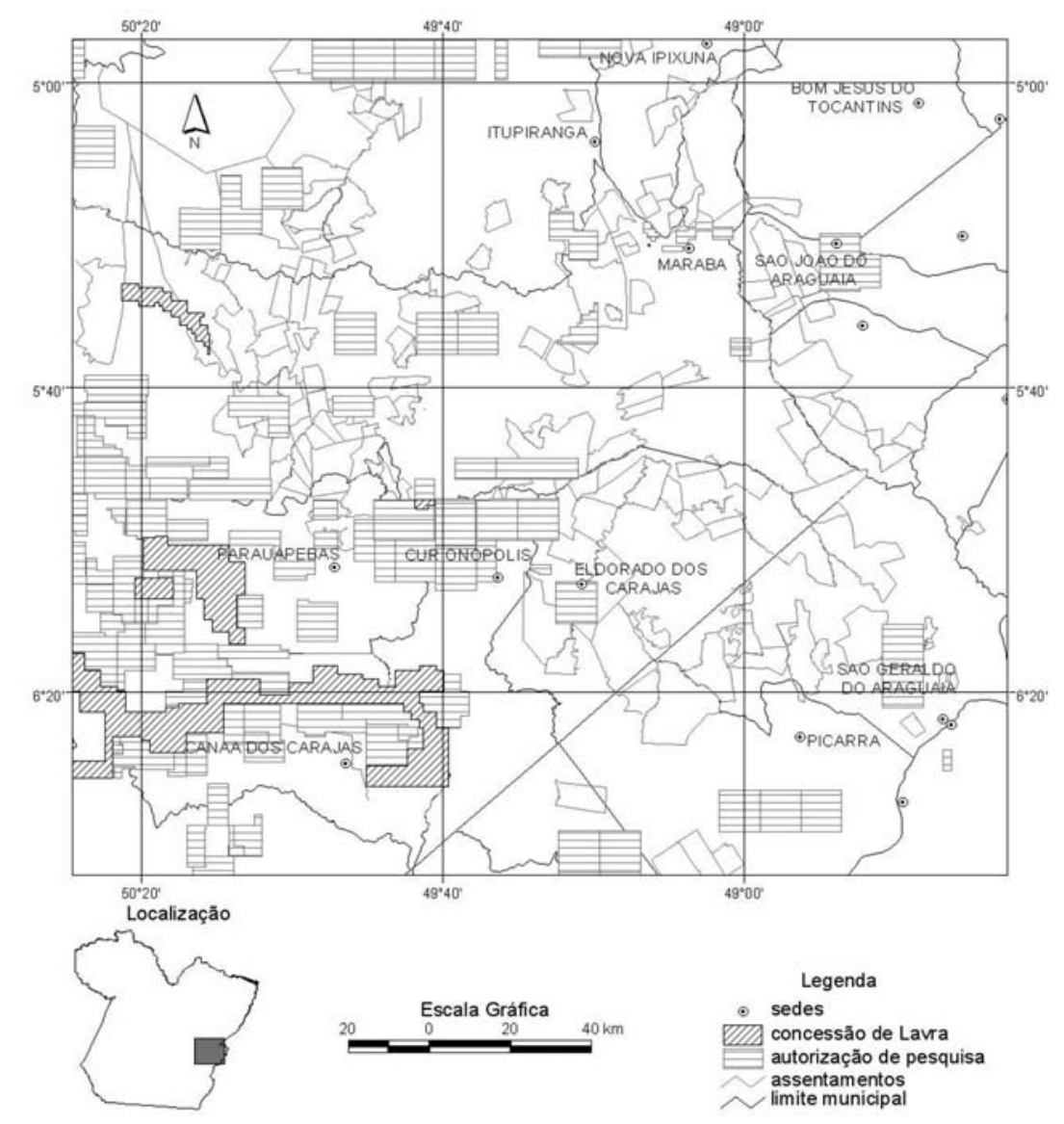

Figura 1. Mapa com indicações da localização dos interesses minerários e de assentamentos em área do sudeste paraense

Raízes, Campina Grande, vol. 25, ns 1 e 2, p. 48-54, jan./dez. 2006 


\section{0 \\ Maurílio de Abreu Monteiro e Sheila do Socorro Lima Teixeira}

to regional. Por outro lado, Costa (1994) e Hurtienne (2001) apontam que esta não é uma dinâmica inexorável e que há condições para a estabilização da produção camponesa na região. Os autores indicam a possibilidade de esta atividade ser extremamente relevante para impulsionar processos de desenvolvimento regional.

Há, por conseguinte, construções teóricas distintas relacionadas com o futuro da agricultura familiar na região, sendo divergentes quanto à tendência de desestabilização ou de estabilização da agricultura familiar. Há uma vertente que, inspirada na escola econômica neoclássica, indica que tal produção é instável. Esta instabilidade estaria associada, basicamente, ao fato de que, na região, o processo de estabelecimento da agricultura familiar baseou-se na utilização da terra como recurso abundante, bem como na precariedade da propriedade camponesa. Nestes termos, a distância e o pouco contato com os mercados permitiriam uma sobrevida das atividades agrícolas e extrativas, praticadas pela agricultura familiar. Segundo Homma (2001), quando a produção camponesa entra em contato com as forças de mercado, tende a ser desarticulada ou expulsa para outras áreas.

Há outras visões relacionadas com o futuro da agricultura familiar na região. Como contraponto à noção de instabilidade estrutural da agricultura familiar, foi elaborada uma outra perspectiva analítica que procura demonstrar que existe a estabilização relativa dos agricultores familiares nas diversas fronteiras do Pará. Para Costa (1994), estaria em curso na Amazônia um processo de estabilização relativa da agricultura familiar por meio da complexificação dos sistemas de produção. Tal estabilização estaria relacionada diretamente com o tipo de atividade que desenvolve a agricultura familiar e com sua capacidade de gerenciar os recursos naturais e a força de trabalho familiar. Tais fatores criam diferentes graus de sustentabilidade e estabilidade.

A estabilidade da agricultura familiar, explicada pelas relações de suas estruturas, por ser dinâmica, deve constantemente adaptar-se ao novo, no intuito de elaborar estratégias de reprodução de suas unidades a fim de alcançar as condições necessárias para se incluir nos processos reprodutivos da sociedade global. E assim forjar o que Costa (1994) chama capacidade de permanência da agricultura camponesa no capitalismo. Desta maneira, seus trabalhos rompem definitivamente com a visão de instabilidade camponesa na região.

Hurtienne (2001) argumenta que não se pode apresentar uma generalização em torno da estabilidade, mas que isto estaria vinculado a uma série de condicionantes agroecológicos, socioeconômicos, socioculturais, à idade de colonização e, fundamentalmente, ao fator político-institucional, para explicar a agricultura familiar.

As dinâmicas relacionadas à agricultura familiar produziram no sudeste paraense uma intersecção temporal e geográfica que redunda em processos que se influenciam reciprocamente, tanto em relação à utilização dos recursos naturais quanto em relação à (des)estruturação do espaço. Se em relação ao significado da agricultura familiar na construção do espaço existem divergências, no que se refere ao da exploração dos recursos minerais também ocorrem.

\section{O SIGNIFICADO DA MINERAÇÃO INDUSTRIAL NA ESTRUTURAÇÃO ESPACIAL}

Há linhas de argumentações diferenciadas sobre as repercussões, na região estudada, da exploração industrial de recursos minerais. Uma delas indica que o controle externo da produção de matérias-primas condicionaria a formação de enclaves, ou seja, haveria a formação de uma economia separada da economia local, melhor dizendo, surgiria um território separado de um domínio contido em outro (Coelho, 2000).

Cardoso \& Faletto (1970) caracterizam estes espaços como enclave mineiro, com reduzida capacidade de absorção de mão-de-obra, elevada concentração de capital e de baixos linkages ou ausência destes.

Estudos pioneiros sobre as atividades de mineração na região de Carajás, encontrados em Pinto (1982), IBASE (1983), Cota (1984), Almeida Jr. (1986), Gistelink (1988), Valverde (1989) e Castro \& Hébette (1989), bem como estudos mais recentes, dentre eles Hall (1991), Hébette (1991), Castro et al. (1994), Coelho \& Cota (1997) e Monteiro (2005), pela dimensão e diversidade dos impactos apresentados, sinalizam os limites analíticos do conceito de enclave. Neste sentido, não parece analiticamente profícuo insistir em investigações rigidamente apegadas ao conceito de enclave.

No que concerne à interação da atividade com o desenvolvimento regional, Costa (1994) aponta a mineração industrial como capaz de impulsionar processos de desenvolvimento da região. Contrariamente, Bunker (1985), Coelho (1997) e Monteiro (2005), dentre outros, apontam limites de diversas ordens para a mineração atuar como força capaz de estabelecer dinâmicas que favoreçam o "enraizamento social" de processos de desenvolvimento. 
Todavia, os estudos, em seu conjunto, são muito limitados quanto à análise do entrelaçamento das estruturas sociais decorrentes da implantação destes empreendimentos e às mudanças deles decorrentes, em especial no que se refere à agricultura familiar.

\section{BUSCANDO INFERIR SOBRE OS IMPACTOS DA MINERAÇÃO EM ASSENTAMENTOS}

Para se inferir os impactos decorrentes da implantação de grandes projetos de extração mineral, em relação à estabilidade da produção camponesa, mais especificamente aquela organizada em assentamentos, foi realizada pesquisa de campo nos assentamentos Palmares I, Palmares II, Onalício Barros e Carlos Fonseca (Figura 2).

Intervalo de confiança e nível de confiança formam as definições que nortearam a dimensão da amostra da pesquisa realizada nos assentamentos (REA; PARKER, 2002). O nível de confiança adotado foi de $99 \%$. Estabelecido o pla-

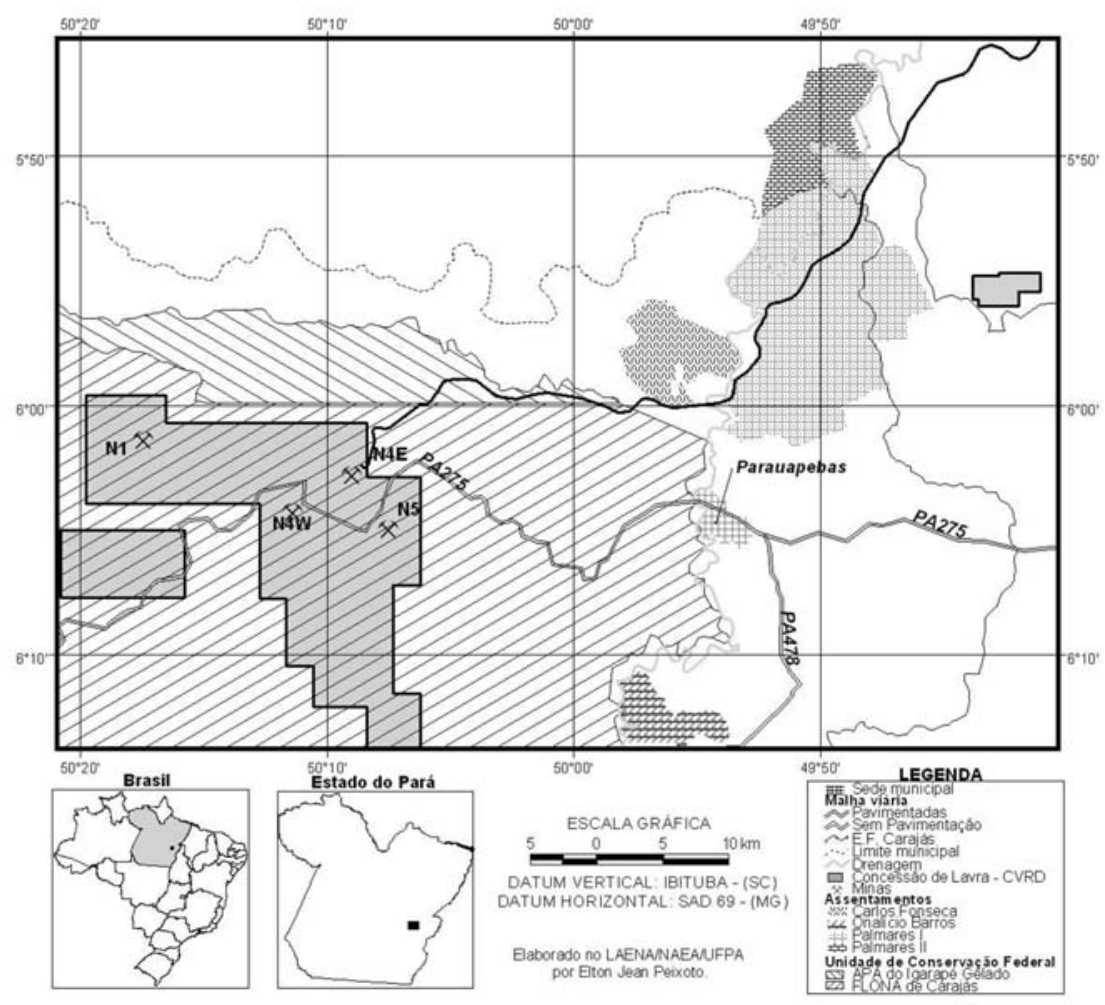

Figura 2. Mapa com a localização de áreas de mineração em Carajás e dos projetos de assentamentos estudados no amostral e elaborado o questionário, nos meses de agosto e setembro de 2005 foram aplicados 296 questionários estruturados, constando de 71 questões. No PA Carlos Fonseca, que atualmente conta com 110 famílias, foram aplicados 45 questionários. No assentamento Palmares I, com o universo de 210 famílias, foram aplicados 83 questionários; no PA Palmares II, que possui 517 famílias, foram aplicados 126 questionários; e no PA Onalício Barros, que possui 68 famílias, foram aplicados 42 questionários.

As informações obtidas em campo foram armazenadas em forma de um banco de dados, sendo realizado, a seguir, tratamento dos dados para se estabelecer relações entre a instalação de empreendimento mineral e as dinâmicas presentes nestes assentamentos. As principais conclusões são apresentadas no item seguinte.

\section{INFLUÊNCIA CONTRADITÓRIA DA MINERAÇÃO NA ESTABILIZAÇÃO DA PRODUÇÃO CAMPONESA}

Dos assentados, 45,94\% chegaram ao sudeste paraense na década de 1990 em busca de terra e trabalho, e $62,84 \%$ foram lavradores noutras áreas antes de serem assentados no sudeste do Pará. São migrantes oriundos, em sua ampla maioria $(61,82 \%)$, do estado do Maranhão; dos restantes, 8,78\% são oriundos do Ceará, 7,77\% do Piauí, e apenas $6,41 \%$ do próprio Pará, os demais se originam de vários outros estados da federação.

A presença da estrada de ferro $\mathrm{Ca}$ rajás, que corta o Maranhão permite o deslocamento de migrantes para $\mathrm{Pa}$ rauapebas, o que podem fazer com baixos custos, constituindo-se em fator adicional para justificar a presença de tão significativo percentual de maranhenses nos assentamentos.

Assim, trata-se de um processo de migração influenciado pela busca de terra que passou a ter como atrator adicional a grande mineração. Uma dinâmica que ganhou contornos organizacionais mais fortes com a participação destes migrantes em movimentos organizados na luta pela terra. 
São agricultores familiares originários de regiões caracterizadas por outros ecossistemas, fator que tem influência direta sobre a capacidade destes lidarem com especificidades do meio ambiente local (Hurtienne, 2005) o que, em curto prazo, dificulta a estabilização da agricultura familiar.

No que concerne à estrutura da unidade familiar, inferiu-se que quase a metade $(49,32 \%)$ dos assentados encontra-se na faixa etária entre 42 e 60 anos; a faixa etária de 18 a 25 representa 4,39\%; a de 26 a 33 anos representa 13,18\%; e a 33 a 41 equivale a 22,97\%. Estas três últimas faixas etárias, primordiais para o fornecimento de força de trabalho, mostraram-se menos expressivas (40,54\%), o que certamente é um elemento que também dificulta a estabilização de unidades camponesas estabelecidas na área estudada.

Dentre os assentamentos, 9,46\% possuem mais de 61 anos. Trata-se de parcela que possui relevância para a estabilidade da agricultura familiar, em especial por ter papel importante na transmissão de conhecimentos tácitos adquiridos com o trabalho na terra. Todavia, neste segmento etário, foi comum, durante as entrevistas, ouvir que seus descendentes seriam pouco afeitos a este trabalho.

No que se refere à dimensão da prole, mais de um terço dos assentados $(37,16 \%)$ tem entre 5 e 10 filhos, todavia, quase a metade $(43,58 \%)$ possui entre 2 e 4 filhos. Uma constatação que corrobora a tendência de redução do número de membros das famílias no agrário brasileiro.

Ainda no âmbito das características da unidade familiar, constatou-se que apenas $11,48 \%$ dos filhos dos assentados vivem no lote e dele sobrevivem. Isto pode ser tomado como um indicador de elevado grau de instabilidade da agricultura familiar nestes assentamentos, já que os filhos de assentados começam a desenvolver atividades que se mostram incompatíveis com a sua manutenção no lote. Para compensar a redução de braços à disposição do trabalho no lote, decorrente da pouca presença dos mais jovens nas atividades agrícolas, há possibilidade de aqueles membros que trabalham fora remeterem parte dos rendimentos auferidos para serem aplicados no campo. Um indício disto é que a contratação de força de trabalho externa a familiar ocorre em 46,62\% das unidades, todavia, esta contratação não acontece de forma generalizada e se dá, especialmente, na fase da colheita, com raras exceções em outras épocas.

Os assentados têm como atividade principal a agricultura, sendo considerada por $60,47 \%$ a principal fonte de renda. As atividades agrícolas temporárias são praticadas em
$76,79 \%$ dos lotes e as culturas permanentes, já igualmente expressivas, estão presentes em 74,66\%. A pecuária mostrase expressiva, representando, segundo estimativa dos assentados, 30,74\% dos rendimentos da unidade familiar. $\mathrm{Na}$ avaliação dos assentados, a presença das culturas temporárias no lote vincula-se, sobretudo, ao abastecimento próprio e à possibilidade de venda do excedente; já a presença e a ampliação da pecuária decorrem do fato de que esta atividade despende menos força de trabalho do que as atividades agrícolas. A este aspecto eles acrescentam a indicação de que os solos pobres dificultam a manutenção da produtividade da agricultura temporária sem que se lance mão do uso de fertilizantes e de agrotóxicos e que tal limitação é menor quando se trata da pecuária, além do fato de que o gado pode ser facilmente vendido no caso de uma necessidade de gasto emergencial.

Tais comportamentos denotam a capacidade de diversificação das atividades, bem como a habilidade de gerenciar os recursos naturais e a força de trabalho familiar, fatores que, de acordo com Costa (1994), concorrem para a manutenção da estabilidade da produção camponesa. Por outro lado, a ampliação da atividade pecuária no âmbito da unidade familiar, além de certos limites, pode ser uma estratégia que concorra para comprometer a estabilização da produção camponesa, pois a manutenção das pastagens por períodos superiores a dez anos só é possível com a utilização de insumos e mecanização, que, para a agricultura familiar, pode tornar-se totalmente inviável, em função de seu alto custo (Costa, 2000).

Evidenciam-se, assim, dinâmicas que expressam uma provável complexificação da agricultura familiar na região estudada, o que é um indicador de estabilidade desta estrutura produtiva. Neste caso, provavelmente a presença da grande mineração e, juntamente com ela, o crescimento demográfico ampliaram a diversidade da demanda por produtos agrícolas. Esta procura está sendo suprida, em parte, pelos assentados e contribuindo para a estabilização das unidades camponesas, pois foram gestadas formas de comercialização direta da produção da agricultura familiar reduzindo, sobremaneira, a participação do capital mercantil nas transações. A "Feira do Produtor", na sede municipal de Parauapebas, é o principal local de venda dos produtos oriundos dos assentamentos, sendo responsável por $40,20 \%$ do recebimento e venda destes produtos. O comércio local, em suas diversas formas, também é o destino de $20,27 \%$ da produção dos assentados.

No que se refere à venda de produtos para a CVRD ou para suas contratadas, esta é muito limitada Em termos 
médios, apenas $2,70 \%$ dos assentados já tinham vendido produtos para a mineradora ou para uma de suas contratadas. Este percentual é mais elevado no PA Carlos Fonseca, no qual a presença desta relação foi constatada entre $4,44 \%$ dos assentados.

No que se refere a outras formas de relacionamento com a CVRD, inferiu-se que 6,76\% mantêm alguma relação com a empresa, ao passo que $90,54 \%$ nunca mantiveram relação de qualquer nível. No PA Palmares I, $13,25 \%$ são os assentados que mantiveram ou mantêm alguma relação direta ou indireta com a CVRD. Neste assentamento há filhos de assentados que trabalham para empresas prestadoras de serviço para a CVRD. Eles realizam trabalhos braçais nas construções e ampliações da estrada de ferro ou de vigilância. Quando indagados se já houve algum problema de ordem econômica, social ou ambiental com a CVRD, 55,06\% responderam que sim.

Inferiu-se que os assentados contam com elevado nível de engajamento em organizações, já que 59,78\% deles estão filiados a alguma entidade regional, com destaque para o Movimento dos Sem Terra (MST), ao qual mais de um terço $(34,12 \%)$ dos assentados são filiados, e para a FETAGRI que conta com a filiação de $11,48 \%$ deles. A tal fato se acresce a constatação de 99,66\% destes assentados estarem ligados às associações locais. Todavia, esta dinâmica associativa não é utilizada para aprimorar processos produtivos e aporta-lhes maior prudência ecológica e eficácia produtiva, oferecendo maior estabilidade à unidade produtiva familiar, pois a associação entre agricultores familiares, no geral, tem como foco reivindicativo principal crédito e infra-estrutura.

\section{CONSIDERAÇÕES FINAIS}

Constatou-se que há influência dicotômica e contraditória da mineração sobre as trajetórias camponesas no sudeste paraense, uma vez que amplia o volume e a diversidade da demanda de produtos da agricultura familiar, favorecendo a complexificação da sua estrutura produtiva. No entanto, os maiores impactos da mineração nas trajetórias camponesas reforçam sua instabilidade, pois colaboram na atração da força de trabalho para outras atividades, alterando a disponibilidade na unidade familiar para realização de trabalho no lote, o que, sabidamente, é um dos pilares da reprodução e estabilidade da produção camponesa.

\section{REFERÊNCIAS BIBLIOGRÁFICAS}

ABRAMOVAY. R. Paradigmas do capitalismo agrário em questão. São Paulo: HUCITEC/UNICAMP; Rio de Janeiro: ANPOCS, 1992. 276p.

ALMEIDA, A. W. B. de. Estrututra fundiária e expansão camponesa In: ALMEIDA JR. J. M. G. de (Org.). Carajás: desafio político, ecologia e desenvolvimento. São Paulo: Brasiliense/CNPq, 1986. v.1. p.265-293.

BOSERUP, E. Evolução Agrária e Pressão Demográfica. São Paulo: Hucitec/Polis, 1987. 141p.

BOURDIEU, P. O poder simbólico. 1.ed.. Rio de Janeiro: Bertran Brasil, 1989. 322p.

BUNKER, S. G. Underdeveloping the Amazon: extraction, unequal Exchange, and the failure of the modern state. United States os América: University of Illinois,1985. 296p.

CARDOSO, F. H.; FALETTO, E. Dependência e desenvolvimento na América Latina. Rio de Janeiro: Guanabara, $1970.143 \mathrm{p}$.

CASTRO, E. Citoyenneté, Societé Civile et Mouvements Sociaux au Brésil. In: Marques-Pereira, B.; Bizberg, I. (Ogrs). La Citoyenneté Sociale en Amérique latine. Paris: LHARMATTAN, CELA-IS. Traduzido por Catherine Prost. Divulgado como paper do NAEA, n. 54. Belém: NAEA/UFPA, 2001.

CASTRO, E. M. R. de, HÉBETTE, J. (orgs.). Na trilha dos grandes projetos: modernização e conflito na Amazônia. Belém: UFPA/NAEA, 1989. 252p.

CASTRO, E.; MOURA, E.; MAIA, M. L. S. Industrialização e grandes projetos: desorganização e reorganização do espaço. Belém: UFPA, 1994. 410p.

CHAYANOV, A. Sobre la teoria de los sistemas econômicos no capitalistas In: ARICÓ, J. (org) Chayanov y la teoria de la economía campesina. México DF: Siglo XXI, 1981.p.49-79.

COELHO, M. C. N. A CVRD e o processo de (re)estruturação e mudança na área de Carajás (Pará). In: Coelho, M. C. N, Cota, R. G. (orgs). Dez Anos de 
Estrada de Ferro Carajás. Belém: UFPA/NAEA, Gráfica Supercores, 1997. p.51-78.

COELHO, M. C. N. Política e gestão ambiental (des) integrada dos Recursos Naturais na Amazônia Oriental. In: Coelho, M. C. N., Simonian, L., Fenzel, N. (Orgs). Estado e Políticas Públicas na Amazônia: Gestão de Recursos Naturais. Belém: Cejup: UFPA/NAEA, 2000p. 117-170.

COELHO, M. C. N., COTA, R. G. (Orgs.). Dez anos da estrada de ferro Carajás. Belém: UFPA/NAEA, 1997. 356p.

COSTA, F. A. A racionalidade camponesa e sustentabilidade: elementos teóricos para uma pesquisa sobre a agricultura familiar na Amazônia. In: Cadernos do NAEA. Revista do NAEA, Belém, n.2, p.5-48, 1994.

CostA, J. M. M. Grandes Projetos e o crescimento da indústria na Amazônia. Belém: MPEG, 1994. p.413-425,

COTA, R. G. Carajás: a invasão desarmada. Petrópolis: Vozes, 1984. 163p.

GISTELINCK, F. Carajás, usinas e favelas. São Luís: Minerva, 1988.

HALL, A. l. Amazônia: desenvolvimento para quem? Desmatamento e conflito social no Programa Grande Carajás. Rio de Janeiro: Jorge Zahar, 1991. 300p.

HÉBETTE, J. O cerco está se fechando. Rio de Janeiro: Vozes, 1991. 347p.

HOMMA, A.K.O. Amazônia: meio ambiente e desenvolvimento agrícola. 1.ed. Brasília: Embrapa-SPI, 1998. 412p.

HOMMA, A. K. O.; CARVALHO, R. A.; MENEZES, A. J. E. A. O custo da produção da banana no sudeste paraense. Belém: Embrapa Amazônia Oriental, 2001.2p.

HURTIENNE, T. P. Agricultura Familiar e Desenvolvimento Rural Sustentável na Amazônia. In: Coelho, M. C. N.; Mathis, A.; Castro, E.; Hurtienne, T. (orgs). Estado e Políticas Públicas na Amazônia: gestão do desenvolvimento regional. Belém: Cejup: UFPA/NAEA, 2001. p.177-283.

IBASE. Carajás: o Brasil hipoteca o seu futuro. Rio de
Janeiro: Achiame, 1983. 157p.

MARX, K. O Capital: Crítica da Economia Política. Livro III, v.VI: O processo global da produção capitalista. Tradução de Reginaldo Sant'Anna. 4.ed. São Paulo: Difel. 1985. 707p.

MONTEIRO, M. de A. Meio século de mineração industrial na Amazônia e suas implicações para o desenvolvimento regional. Estudos Avançados/USP, São Paulo, v.19, n.53, p.189-207,. 2005.

MONTEIRO, M. de A. Problemas e perspectivas da verticalização da produção da hematita na Amazônia oriental brasileira: o caso da produção de ferro-gusa. In: Klein, E. L, Vasquez, M. L., Rosa-Costa, L. T. (org.) Contribuições à Geologia da Amazônia. Belém: Sociedade Brasileira de Geologia - Núcleo Norte (SBG - NO), 2002, v.3. p.23-32.

PINTO, L. F. Amazônia: a fronteira do caos. Belém, 1992. 159p.

REA, L. M.; PARKER, R. A. Metodologia de Pesquisa: do planejamento à execução. São Paulo: Pioneira Thomson Learning, 2002. 272p.

SERRÃO, E. A. Desenvolvimento agropecuário e florestal na Amazônia: proposta para o desenvolvimento sustentável com base no conhecimento científico e tecnológico. In.: Costa, J. M. M. da. Amazônia: desenvolvimento econômico, desenvolvimento sustentável e sustentabilidade de recursos naturais. Belém - Pará, 1995.

SOJA, E. Geografias Pós-Modernas. Rio de Janeiro: Zahar, 1993. 324p.

VALVERDE, O. Grande Carajás: planejamento da destruição. Rio de Janeiro: Forense Universitária, 1989. 154p.

VELHO, O. G. Capitalismo autoritário e o campesinato. São Paulo: Difel, 1976. 261p.

WALKER, R. Land use dynamics in the Brazilian amazon. In: Ecological Economics, 1996.p. 01-02.

WANDERLEY, M. N. B. Raízes históricas do campesinato brasileiro. In: Tedesco, J. C. (org). Agricultura Familiar: realidades e perspectivas. Passo Fundo: EDIUPF, 1999. 